\title{
Execution of a smart street lighting system for energy saving enhancement
}

\author{
Ihab Abdulrahman Satam, Suhail N. Shahab, Haider A. Kamel, Mokhaled N. A. Al-Hamadani \\ Department of Electronics Techniques, Al-Hawija Technical Institute, Northern Technical University, Iraq
}

\begin{tabular}{l}
\hline Article Info \\
\hline Article history: \\
Received Feb 27, 2021 \\
Revised May 9, 2021 \\
Accepted May 24, 2021 \\
\hline
\end{tabular}

Keywords:

Arduino

Energy saving

Fuzzy logic

IR sensors

Smart light

Smart system

\begin{abstract}
In many countries, particularly, third world countries. The common issue is saving energy. That's why smart systems considered now primary for life requirements. This work aims to solve the energy saving problem. We prepared a street model that contains several lampposts on both sides of the street; we placed three IR sensors between the lampposts alongside the street. The IR sensors are connected to the controller (in this work we used Arduino UNO). The controller takes the signal from the IR sensor, and then it sends the command to the lamppost to turn on or off. Depending on the number of cars passed, (we took a sample of a number of cars that passed on an actual street) and through formulas we calculated the power consumed by the lampposts in two cases, the first case is when the lights is always on. The second case is when the smart system applied. We also applied fuzzy logic to the system to take the intensity of the ambient light (the sun light) under consideration. The results showed that the proposed smart lighting system is efficient and reliable in saving energy. The energy saved for both (smart and fuzzy) systems was enormous.
\end{abstract}

This is an open access article under the CC BY-SA license.

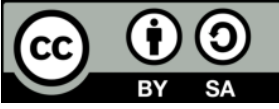

\section{Corresponding Author:}

Ihab Abdulrahman Satam

Electronics Techniques Department

Technical Institute/Al-Hawija, Northern Technical University Mosul, Iraq

Email: ihab_hwj@ntu.edu.iq

\section{INTRODUCTION}

With the high quick-advancement in technology and the rising in the living criteria, the city environment claims are rising as well. That's why the smart system technology showed up. Every smart system combine different kinds of technologies, such as computer, control and informations [1]-[5]. Most of the smart system applications preferred the wireless mode, however the wireless mode is used as well. The cable limitation issues and the scalability of the system makes the wireless mode is widely used [6], [7]. Rajput $e t a l$. worked on what is called intelligent street lighting. The problem with this system is that it can work only with low traffic [8]. Archana Tripathy`s work concentrate on the sensors and the smart system hardware, the researcher made some comparison with explanations of advantages and disadvantages between traditional and smart lighting system (SLS) [9]. Lwin et al. worked on a SLS for improving visual comfort [10]. The purpose of this work is to implement a SLS for a street that control the lamppost light on and off depending on the number of objects passed through the street, in order to reduce wasting energy.

\section{RESEARCH METHOD}

The system proposed in this paper contains 3 active IR sensors that consider as the eye of the system. The sensor used to detect the object crossing the street. The system brain is the Arduino controller 
that organize the system work to take the signal from sensor, process it and sends the output to the actuator, which is in this paper is the Lamposts.

\subsection{System building}

The structure of the system was build using several components which will be explained in details:

a. Arduino uno: it is an open source board that is easy to install, connect and program. It contains 14 digital pins with 6 analogue pins an the power can be pluged into it through a usb port or simply connect a 9v battery through the charging port. Figure 1 shows the Arduino controller [11].

b. IR sensor: an electronic device that uses emitting to sense the surroundings. It can measure the heat as well as detect the motion of the objects. The device consist's of two parts: emitter to emit the thermal radiation and the receiver to detect the reflected radiations after hitting the object as illustrated in Figure 2. The sensor`s output voltage will change as how much the magnitude of the resistance will change depending on the rate of IR light received $b$ the photodiode of the IR LED [12].

c. Light emitting diode (LED): Figure 3 demonstrates a simple semiconductor that has simple working principle: when the current flows into it, it produce light. This semiconductor has both P-Type (that represent the hole concentration) and N-Type (which represent the electron concentration). When a sufficient amount of voltage is applied the holes and electrons will recombine at the P-N junction area, releasing energy as light form [13].

d. Light dependent resistor (LDR): a cell that belongs to the Photoconductive family, it has a piece of exposed semiconductor material. The work principle of LDR is that it decreases resistance when receiving light on the component sensitive surface [14]-[20].

e. Extra parts: extra parts such as wires, breadboard and batteries. They used to connect and power the system.

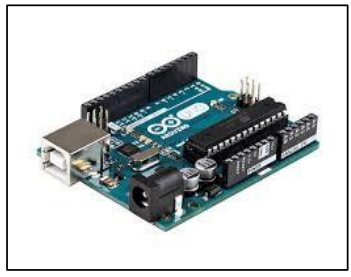

Figure 1. Arduino

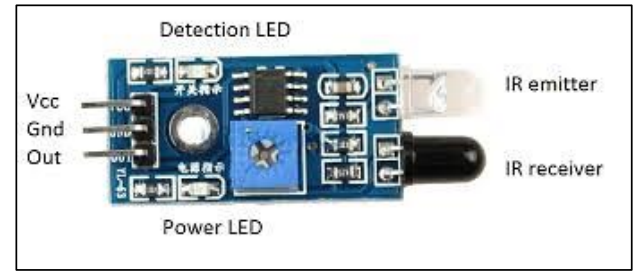

Figure 2. IR sensor

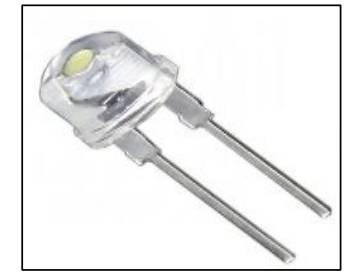

Figure 3. Light emitting diode

\subsection{Fuzzy logic}

Fuzzy logic is considered as a very strong tool in dealing with complex problem. Nowadays, the deduction role in solving suspicion in engineering applications took big place in scientist's interests. Fuzzy logic was first introduced by Lotfi Zadeh in 1965. His work "Linguistic Approach" and "A rationale for Fuzzy control" helped and motivated scientists in their pioneer work. Fuzzy logic architecture as shown in Figure 4 has four parts [21]-[26]:

a. Fuzzification module: transform the inputs of the system to fuzzy sets.

b. Knowledge base: stores the rules of IF-THEN

c. Inference engine: simulate the process of human reasoning by making fuzzy conclusions on the inputs and the rules of IF-THEN [27]-[30].

d. Defuzzification module: transforms the fuzzy set to crisp values.

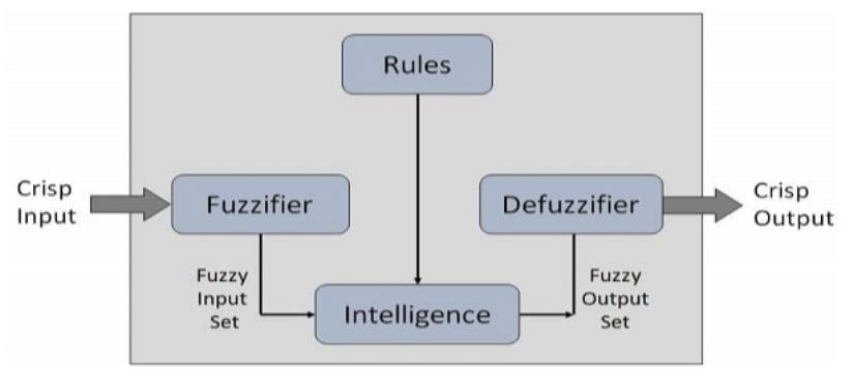

Figure 4. Fuzzy logic architecture 


\subsection{Experimental work}

The experimental work was done in two parts: the first part was implementing a standard smart system using IR sensor and Arduino, the second part was applying fuzzy logic for the smart system and calculate the difference in power consumption between the two systems. But before that we need to test the IR sensor accuracy and how much the system can depend on it.

\subsubsection{Sensor accuracy}

As we know, one of the IR sensor uses is to measure distance. To calculate accuracy of the sensor, we used several objects on different distances and used the sensor to measure the distance, then we compared it with the real distance, in order to evaluate the error difference between real and actual distance. Table 1 and Figure 5 shows the sensor accuracy. The sensor performance is accurate and linear, within $0.09 \mathrm{~cm}$ error at worst case scenario that the object is very far from the sensor.

Table 1. Difference between real and actual distance

\begin{tabular}{cccc}
\hline Object \# & Real Distance & Actual Distance & Error \\
\hline 1 & $3 \mathrm{~cm}$ & $2.98 \mathrm{~cm}$ & 0.02 \\
2 & $3.5 \mathrm{~cm}$ & $3.49 \mathrm{~cm}$ & 0.01 \\
3 & $4 \mathrm{~cm}$ & $4 \mathrm{~cm}$ & 0 \\
4 & $4.5 \mathrm{~cm}$ & $4.495 \mathrm{~cm}$ & 0.005 \\
5 & $5 \mathrm{~cm}$ & $4.8 \mathrm{~cm}$ & 0.07 \\
6 & $5.5 \mathrm{~cm}$ & $5.25 \mathrm{~cm}$ & 0.09 \\
\hline
\end{tabular}

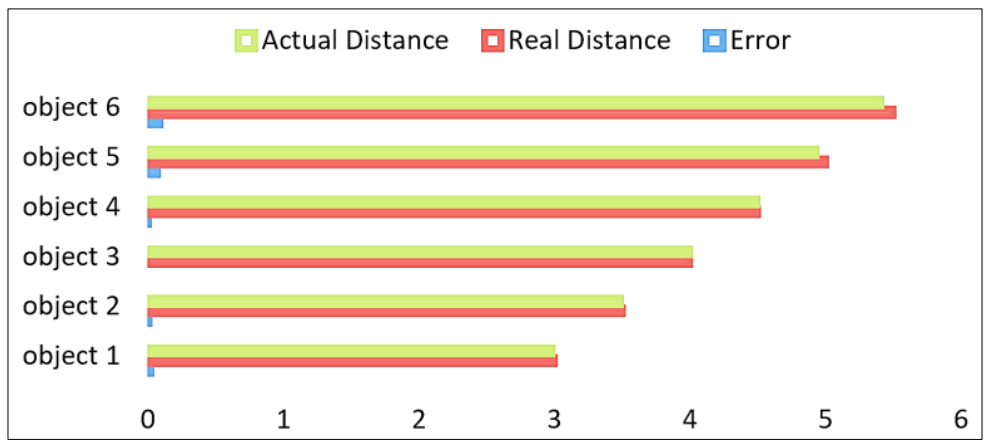

Figure 5. IR sensor accuracy

\subsubsection{Standard smart system}

The smart lighting system consists of several Lampposts that placed on both sides of the street. The Three IR sensors positioned in different spots between the lampposts. The purpose of this is that the IR sensor can detect the objects or cars passed through the street. The functioning of IR sensor as shown in Figure 6 can be explained as follow:

a. The sensor consist of IR LED and IR photodiode.

b. IR Led will emits radiation.

c. The radiation hits the object, then it reflect back.

d. The receiver will detect the reflected radiation. The intensity of the received radiation will determine the amount of output voltage.

The sensor electronic circuit is shown in Figure 7. The circuit has: IR Led, op-amp IC, LED and photodiode. When the reflected IR light is detected by the photodiode Op-Amp IC will work as a voltage comparator, the potentiometer will adjust the yield of the sensor. Figures 8 and 9 shows the actual smart lighting system that installed on a street model. In addition, the flowchart of the smart lighting system is shown in Figure 10. The flowchart explain the system functioning method:

a. The object crosses the first IR sensor, the controller sends the command to the Lampposts number 1,2 and 3 to be ON

b. The object now crosses the second IR sensor, the Arduino now sends the commands to Lampposts number 4, 5 and 6 to be ON. While the first three will be-OFF.

c. The objects reaches the third IR sensors. The Lampposts number 7, 8 and 9 will be ON, while the previous LEDs will be OFF. 


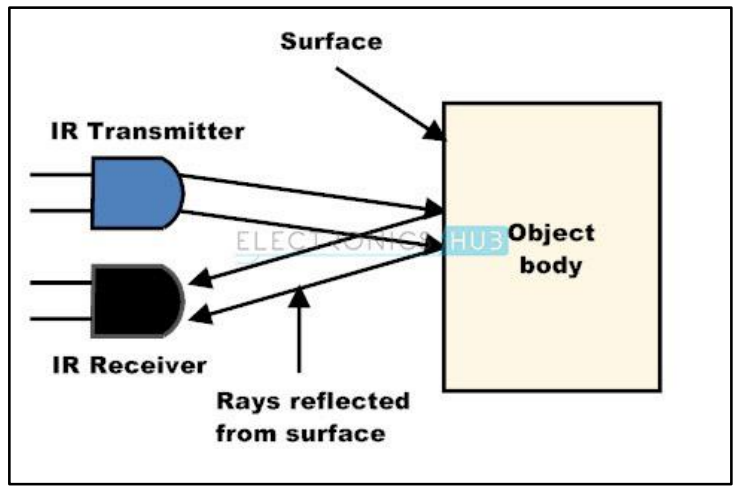

Figure 6. IR functioning method

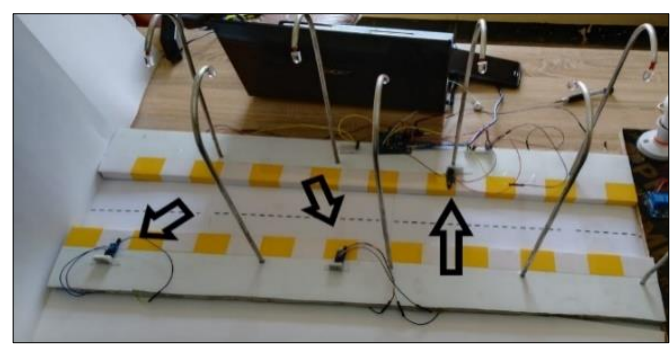

Figure 8 . The actual smart lighting system model

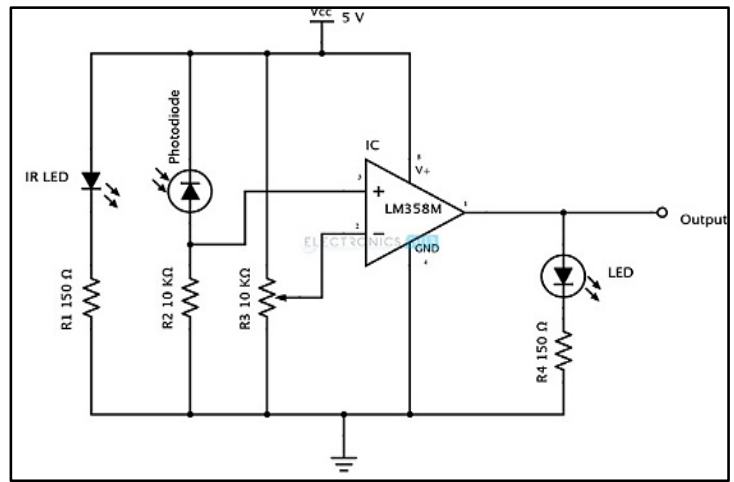

Figure 7. Electronic circuit of the IR sensor

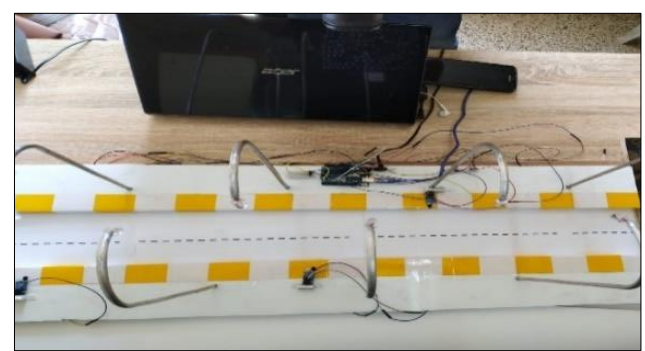

Figure 9. The complete system

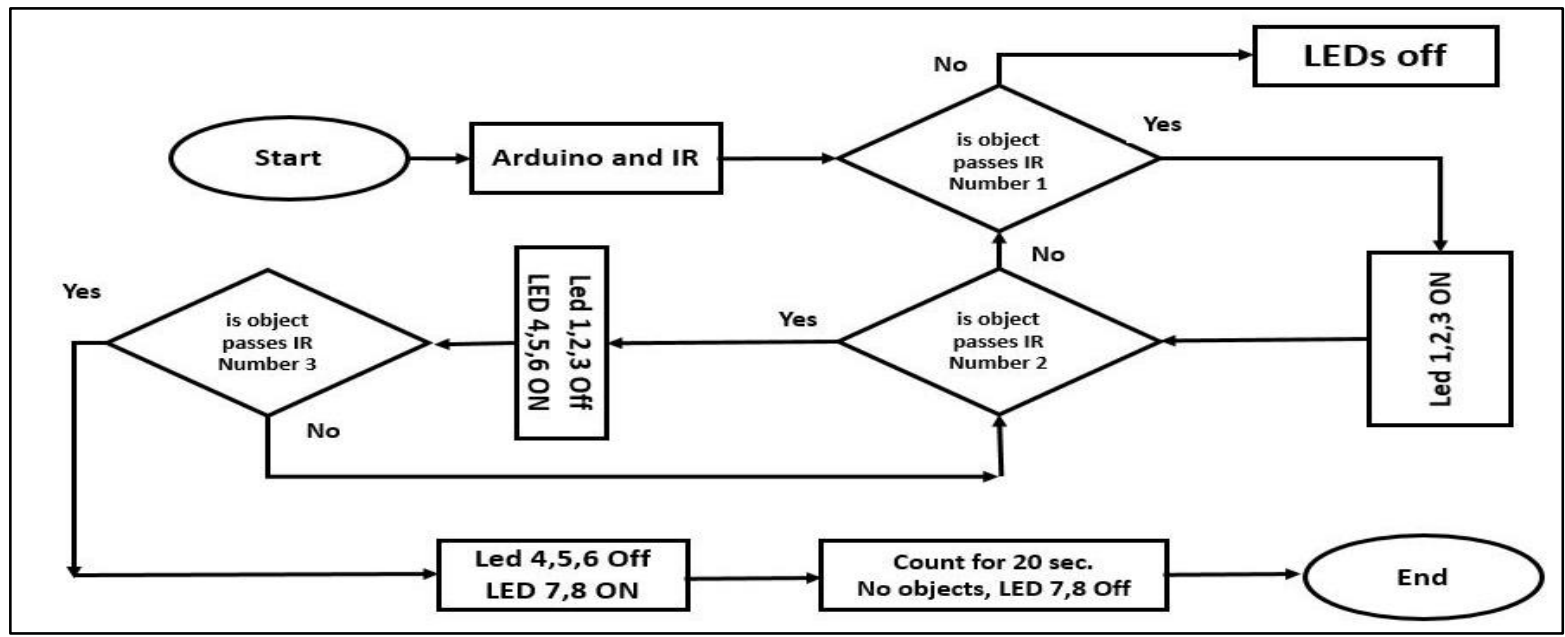

Figure 10. Smart lighting flow chart

\subsubsection{Applying fuzzy logic on the smart system}

Before applying fuzzy logic to the smart system, the intensity detection must be considered. The LEDs are switched ON and OFF with respect to intensity of the natural light. For that matter an LDR sensor is used for ambient intensity detection. In this paper we classified the level of lighting to three levels.

a. Low light; in this condition, only $25 \% \%$ of the LEDs light will flare. The time of this condition can be noticed between (5-6) P.M. at this time the light from the sun will still has effect on vision. So no need for the LEDs to be fully ON.

b. Medium light; in this condition $50 \%$ of the LEDs light will flare. The condition is approximately between (6-8) P.M.

c. High light; this condition make the LEDs at full percentage ON, which means $100 \%$. The time for this condition is ( 8 pm-6 am). Table 2 shows the inputs and outputs linguistics variable for the fuzzy. For the Sun light the fuzzy set are V.Low (very low), low, medium, high and V.high (very high). For the cars or the objects the fuzzy set is (pass, not pass). Finally, the output for LEDs light will be high, medium and 
low. While, Table 3 presents the fuzzy logic rules applied in this paper. Figure 11 and 12 shows the applied input to the fuzzy input.

Table 2. Inputs and outputs linguistics variable for the fuzzy

\begin{tabular}{lll}
\hline Parameter & Linguistic Variable & \multicolumn{1}{c}{ Fuzzy set } \\
\hline \multirow{2}{*}{ Input } & Sun light (SL) & V.low, low, medium, high, V.high \\
Output & Cars or object (C) & Pass, not pass \\
\hline
\end{tabular}

Table 3. The fuzzy rule base for smart lighting system

\begin{tabular}{cl}
\hline No & \multicolumn{1}{c}{ Rule } \\
\hline 1 & If SL is V.Low AND C is Pass Then L is High \\
2 & If SL is Low And C is Pass THEN L is Medium \\
3 & If SL is Medium AND C is Pass THEN L is Low \\
4 & If SL is High And C is Pass THEN L is Low \\
5 & If SL is V.High and C is Pass THEN L is Low \\
6 & If SL is V.Low and C is Not Pass THEN L is Low \\
7 & If SL is Low and C is Not Pass THEN L is Low \\
8 & If SL is Medium and C is Not Pass THEN L is Low \\
9 & If SL is High and C is Not Pass THEN L is Low \\
10 & If SL is V.High and C is Not Pass THEN L is Low
\end{tabular}

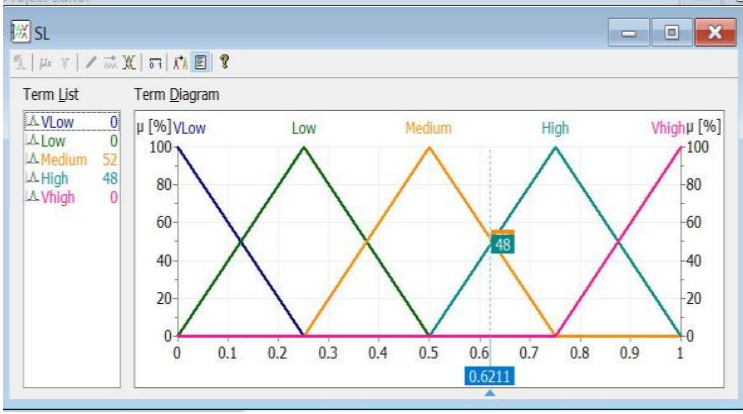

Figure 11. Input number 1

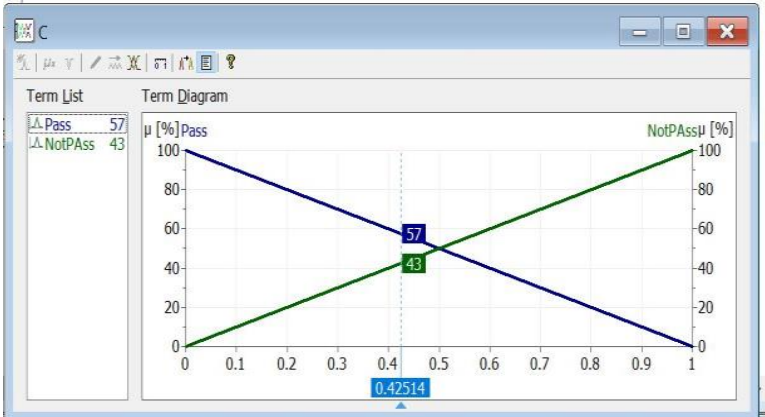

Figure 12. Input number 2

\subsection{System software}

In this paper we used Arduino IDE (integrated development environment) Software to program the Arduino controller. The software is an open source software, the program written will be saved as a file extension (.ino). For the fuzzy logic controller, MaTLab Software used to apply the fuzzy rules for the system.

\section{RESULTS AND DISCUSSION}

\subsection{Energy saving using standard smart system}

In this paper we used a model street, however we made observations for an actual street, then we applied it on the model street. We calculated the number of cars passed through the actual street during the daily hours. We found out that the number of cars passed are as follows:

a. From 6-10 pm: 88 cars passed.

b. From 10 pm-2 am: 44 cars passed.

c. From 2-6 am: 14 cars passed.

We applied the same amount of objects passed on the module. Using power calculations formulas we determined the amount of energy saved. The calculation procedure were:

a. In the first 4 hours, the number of cars in one-hour can be obtained:

$$
\text { No of cars per hour }=\frac{\text { No.of cars through specific time }}{\text { Number of hours }}=(84 / 4=22 \text { car } / \text { hour })
$$

b. Average minute per car can be obtained:

$$
\text { Average minute per car }=\frac{60\left(\frac{\mathrm{min}}{\text { hour }}\right)}{\text { No.of cars per hour }\left(\frac{\mathrm{cars}}{\text { hour }}\right)}
$$


$=(60 / 22=3$ minutes per car approximately $)$

c. In the software, we set the delay time for the LED to be on is $30 \mathrm{sec}$.

Number of minutes the cars passed through the sensor $=\frac{60}{3}=(20$ minutes $)$

The time period the led will be on $=$ Delay $*$ Number of minutes

LED will be on for $(30 * 20=600 \mathrm{sec})$

The total Time the leds will be on $=$ Time of one LEd $*$ Number of leds $=60 * 4=2400 \mathrm{sec}$

$2400 \mathrm{sec}$ equal to $0.67 \mathrm{hr}$. We applied (1) to (5) for the other operating hours as shown in Table 4. From the Table 4 we can see the total power consumed is equal to $1.0848 \mathrm{~W}$.

Table 4. Comparison between traditional energy consumption and smart light energy consumption

\begin{tabular}{cccccc}
\hline $\begin{array}{c}\text { Consumption } \\
\text { method }\end{array}$ & $\begin{array}{c}\text { Number of } \\
\text { LED }\end{array}$ & $\begin{array}{c}\text { Voltage per } \\
\text { LED }\end{array}$ & $\begin{array}{c}\text { Ampere Per } \\
\text { LED }\end{array}$ & $\begin{array}{c}\text { Number of } \\
\text { Hours }\end{array}$ & \multicolumn{2}{c}{$\begin{array}{c}\text { Power } \\
\text { consumed }\end{array}$} & $\begin{array}{c}\text { Total power } \\
\text { Traditional }\end{array}$ & 8 & $1.2 \mathrm{~V}$ & $100 \mathrm{~mA}$ & 12 & $11.52 \mathrm{~W}$ \\
Smart (6-10) pm & 8 & $1.2 \mathrm{~V}$ & $100 \mathrm{~mA}$ & 0.67 & $0.6432 \mathrm{~W}$ \\
Smart(10pm-2am) & 8 & $1.2 \mathrm{~V}$ & $100 \mathrm{~mA}$ & 0.33 & 0.3168 \\
Smart (2-6) am & 8 & $1.2 \mathrm{~V}$ & $100 \mathrm{~mA}$ & 0.13 & 0.1248 \\
\hline
\end{tabular}

From the Table 4 we can conclude that the amount of power saved is $(11.52-1.0848=10.4352 \mathrm{~W})$. this saved energy can be used to power other building or wider populated area. Figures 13 and 14 shows the difference in energy consumption between the regular system and the smart system. Figure 8 shows how the energy consumed in smart system was dropped through the hours. On the contrary the regular system in figure 9 shows how the same amount of energy is consumed in the same period. One of the effects of the wasted energy is the effect in the life time of the Lampposts as well as the cable that transfer the electrical energy.

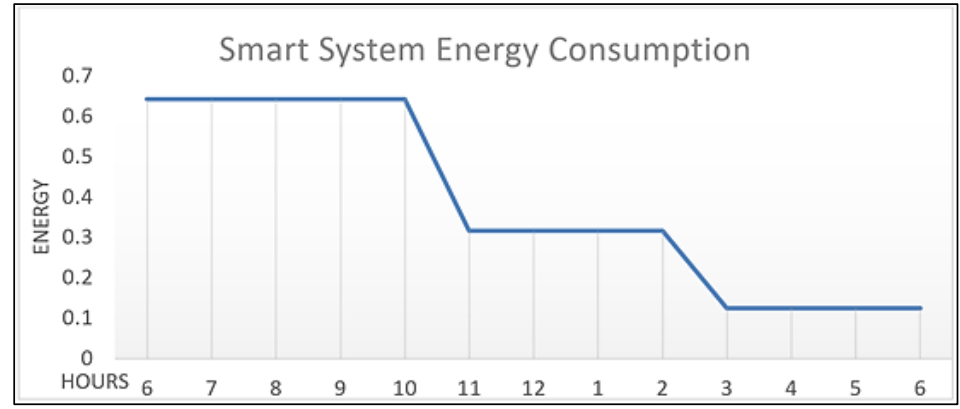

Figure 13. Energy consumption in smart system

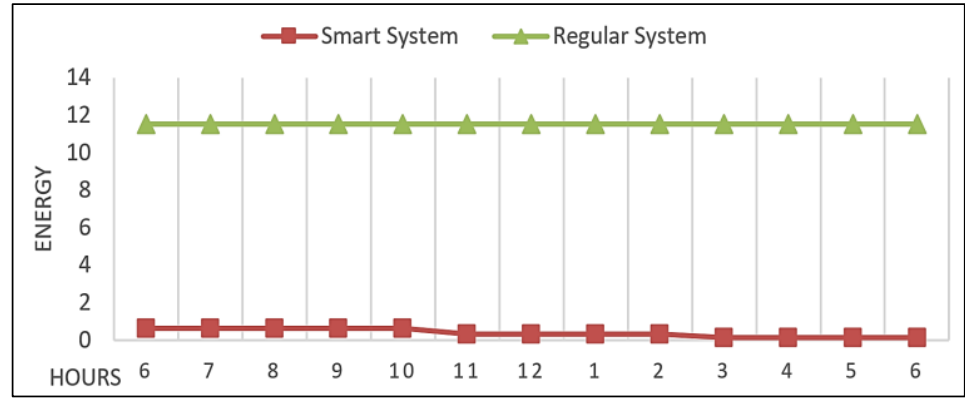

Figure 14. Energy consumption difference

\subsection{Applying fuzzy on the system}

The outcome of the system after applying fuzzy rules is determined according to energy consumption with respect to energy consumption. Figure 15 shows the difference in energy consumption 
between smart system with and without applying fuzzy logic. Figures 16 and 17 show the 3D plot of applying fuzzy logic to the smart system, the data calculated shows a great deal of success in energy saving.

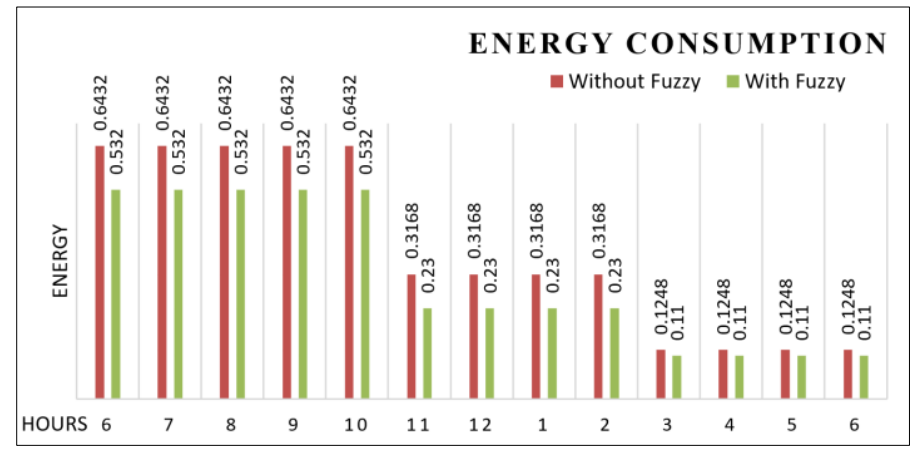

Figure 15. Energy consumption difference using fuzzy logic

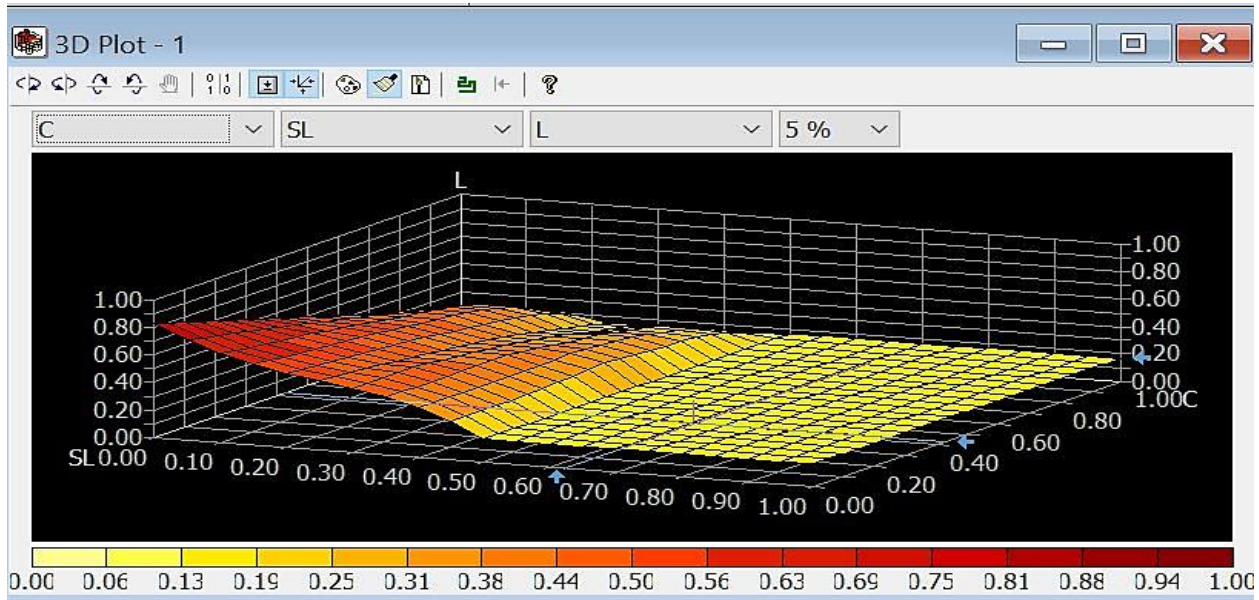

Figure 16. Fuzzy smart lighting system

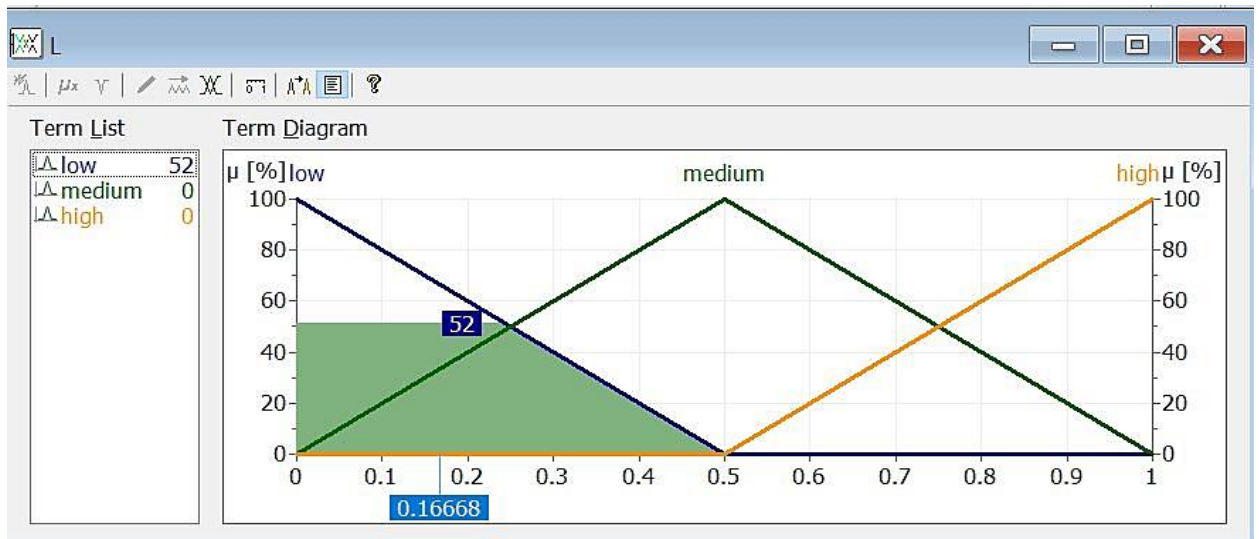

Figure 17. Fuzzy logic output

\section{CONCLUSION}

The main aim of this work is accomplished. The waste of energy in lighting system solved using the smart system, depending on the active IR sensor, and by applying Fuzzy Logic. We can see how much power we can save for one street, how about if we applied it for an entire city. We can add more IR sensor or instead we can add cameras for more accurate object detection. In third world countries, electric power is 
consumed randomly due to lack of understanding of power distribution from the station as well as lack of awareness of the people to save energy. That's why smart system is the most valuable option.

\section{ACKNOWLEDGEMENTS}

We would like thank Northern Technical University, Technical Institute\Al-Hawija labs for the help they provided us to complete this work.

\section{REFERENCES}

[1] J. Kurmi, "Scenario of Home Automation in India," Int. J. Sci. Res. Comput. Sci. Eng. Inf. Technol., vol. 3, no. 3, pp. 381-384, 2020.

[2] C. Lohr and J. Kerdreux, "Improvements of the xAAL home automation system," Future. Internet, vol. 12, no. 6, pp. 1-31, 2020, doi: 10.3390/fi12060104.

[3] G. Piscitelli et al., "A low-cost energy-harvesting sensory headwear useful for tetraplegic people to drive home automation," AEU Int. J. Electron. Commun., vol. 107, pp. 9-14, 2019, doi: 10.1016/j.aeue.2019.05.015

[4] M. Umer and M. M. Khan, "Smart Home Automation Using ATMEGA328," Adv. J. Sci. Eng., vol. 1, no. 3, pp. 86-90, 2020, doi: 10.22034/AJSE2013086.

[5] T. Vignesh, D. Selvakumar, C. Prasath, N. Manikandan, and R. S. Viswanath, "Design and fabrication of home automation," IOP Conf. Ser. Mater. Sci. Eng., vol. 623, no. 1, pp. 1-6, 2019, doi: 10.12928/TELKOMNIKA.v17i6.13142.

[6] Z. G. Faisel, M. S. Hussein, and A. M. Abood, "Design and realization of motion detector system for house security," Telkomnika (Telecommunication Comput. Electron. Control.), vol. 17, no. 6, pp. 3211-3217, 2019.

[7] A. Mayub, Fahmizal, M. Shidiq, U. Y. Oktiawati, and N. R. Rosyid, "Implementation smart home using internet of things," Telkomnika (Telecommunication Comput. Electron. Control.), vol. 17, no. 6, pp. 3126-3136, 2019, doi: 10.12928/telkomnika.v17i6.11722.

[8] P. K. Y. Rajput, G. Khatav, M. Pujari, and P. Yadav, “Intelligent Street Lighting System Using Gsm,” Int. J. Eng. Sci. Invent., vol. 2, no. 3, pp. 60-69, 2013.

[9] A. Tripathy, "Intelegent Smart Lighting System Archana Tripathy," Int. J. Eng. Sci. Invention, vol. 2, no. 3, pp. 82$88,2013$.

[10] L. M. Thet, A. Kumar, N. Xavier and S. K. Panda, "A smart lighting system using wireless sensor actuator network," 2017 Intelligent Systems Conference (IntelliSys), 2017, pp. 217-220, doi: 10.1109/IntelliSys.2017.8324294.

[11] I. A. Satam, M. N. A. Al-Hamadani, and A. H. Ahmed, "Design and implement smart blind stick," J. Adv. Res. Dyn. Control Syst., vol. 11, no. 8, pp. 42-47, 2019.

[12] "IR (Infrared) Obstacle Detection Sensor Circuit." [Online]. Available: https://www.electronicshub.org/ir-sensor/. [Accessed: 06-Jun-2020].

[13] "Light Emitting Diode <What are LEDs and How Do They Work?> | Electronics Basics ROHM." [Online]. Available: https://www.rohm.com/electronics-basics/leds/what-are-leds.[Accessed: 06-Jun-2020].

[14] S. Suherman, F. Purba, R. Dinzi, and R. Fauzi, "Design and analysis of the LDR-controlled device," IOP Conf. Ser. Mater. Sci. Eng., vol. 851, no. 1, 2020, doi: 10.1088/1757-899X/851/1/012011.

[15] S. Ghosh and N. Haldar, "Solar tracking system using AT89C51 microcontroller and LDR," Int. J. Emerg. Technol. Adv. Eng., vol. 4, no. 12, pp. 403-407, 2014.

[16] S. Y. Dauda and A. Z. Loko, "Design and construction of an automatic streetlight controller using microcontroller and LDR,” Int. J. Acad. Res. Dev., vol. 5, no. 3, pp. 50-56, 2020

[17] T. Z. Htwe, A. T. Tun, and C. S. Aung, "Power Saving System Using LDR And PIR Sensor," Iconic Res. Eng. J., vol. 4 , no.2, pp. 51-55, 2020.

[18] C. Huangwei et al., "A New PCR/LDR-Based Multiplex Functional Molecular Marker for Marker-Assisted Breeding in Rice," Rice Sci., vol. 28, no. 1, pp. 6-10, 2021, doi: 10.1016/j.rsci.2020.11.002.

[19] I. Sabri and A. Rashid, "Multi-Robot Localization System using an Array of LEDs and LDR Sensors," Int. J. Comput. Appl., vol. 176, no. 10, pp. 9-12, 2020, doi: 10.5120/ijca2020920001.

[20] M. M. Saputra, D. Yudhawati, and R. S. Aminda, "Effect of Loan To Deposit Ratio (Ldr) and Non Performing Loan (Npl) on Return on Assets (Roa) in bahasa: Pengaruh Loan To Deposit Ratio (Ldr) Dan Non Performing Loan (Npl) Terhadap Return on Asset (Roa)," Manag. J. Ilmu Manaj., vol. 3, no. 1, p. 85, 2020, doi: 10.32832/manager.v3i1.3836.

[21] M. S. Hameed, S. Mukhtar, H. N. Khan, S. Ali, and M. H. Mateen, "Pythagorean Fuzzy N -Soft Groups," Indonesian J. Electr. Eng. Comput. Sci., vol. 21, no. 2, pp. 1030-1038, 2021, doi: 10.11591/ijeecs.v21i2.pp10301038.

[22] G. A. M. Madrigal et al., "Fuzzy logic-based maximum power point tracking solar battery charge controller with backup stand-by AC generator," Indonesian J. Electr. Eng. Comput. Sci., vol. 16, no. 1, pp. 136-146, 2019, doi: 10.11591/ijeecs.v16.i1.pp136-146.

[23] S. S. Sofian and A. S. Rambely, "Measuring perceptions of students toward game and recreational activity using fuzzy conjoint analysis," Indonesian J. Electr. Eng. Comput. Sci., vol. 20, no. 1, pp. 395-404, 2020, doi: 10.11591/ijeecs.v20.i1.pp395-404. 
[24] M. S. C. Lah and N. Arbaiy, "A simulation study of first-order autoregressive to evaluate the performance of measurement error based symmetry triangular fuzzy number," Indonesian J. Electr. Eng. Comput. Sci., vol. 18, no. 3, pp. 1559-1567, 2020, doi: 10.11591/ijeecs.v18.i3.pp1559-1567.

[25] W. R. Abdul-Adheem, "Design and simulation of a normalized fuzzy logic controller for the quadruple-tank process," Indonesian J. Electr. Eng. Comput. Sci., vol. 18, no. 1, pp. 227-234, 2019, doi: 10.11591/ijeecs.v18.i1.pp227-234.

[26] A. Q. Ansari and J. M. Islamia, "The Basics of Fuzzy Logic :A Tutorial Review," Comput. Educ., vol. 88, pp. 5-9, 2015.

[27] H. Hasanzadeh and J. Majidpour, "Application of fuzzy logic in order to plan and create software for Converting sound to text," Bull. Electr. Eng. Informatics, vol. 9, no. 3, pp. 1127-1136, 2020, doi: 10.11591/eei.v9i3.1723.

[28] S. Panigrahi and A. Thakur, "Modeling and simulation of three phases cascaded H-bridge grid-tied PV inverter," Bull. Electr. Eng. Informatics, vol. 8, no. 1, pp. 1-9, 2019, doi: 10.11591/eei.v8i1.1225.

[29] A. A. Baker and Y. Y. Ghadi, "Autonomous system to control a mobile robot," Bull. Electr. Eng. Informatics, vol. 9, no. 4, pp. 1711-1717, 2020, doi: 10.11591/eei.v9i4.2380.

[30] M. K. I. Abd Rahman, M. S. Z. Abidin, M. S. A. Mahmud, S. Buyamin, M. H. I. Ishak, and A. A. Emmanuel, "Advancement of a smart fibrous capillary irrigation management system with an internet of Things integration," Bull. Electr. Eng. Informatics, vol. 8, no. 4, pp. 1402-1410, 2019, doi: 10.11591/eei.v8i4.1606.

\section{BIOGRAPHIES OF AUTHORS}

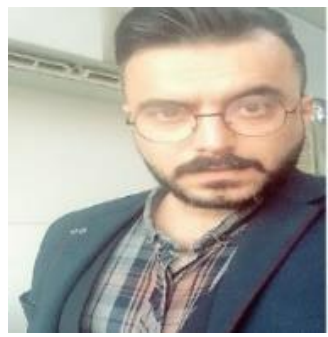

Ihab Abdulrahman Satam B.Sc Mechatronics-Engineering college-University of Mosul-Iraq. M.Sc Mechatronics-Alkhwarizmi Engineering college-University of Baghdad-Iraq. Assistant lecturer-Northern Technical University- Iraq. Research interest. Robotics-Neural Networkcontrol-Autopilot
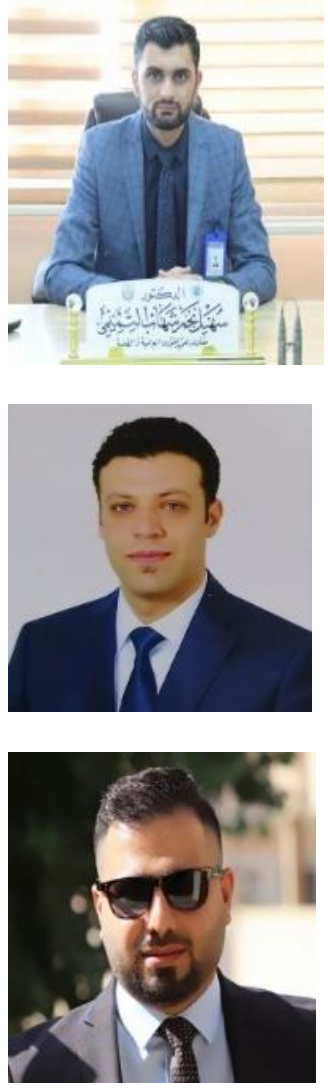

Suhail N. Shahab was born in Kirkuk, Iraq on Feb 1988. He was graduated in 2010 with B. Eng. in Computer Technology Engineering from Al-Hadba'a University College, Mosel, Iraq. In 2013, he received his M.Sc. in Electrical Engineering with a specialization in Wireless Communication from University Tenaga Nasional, Malaysia. Then, he received his Ph.D. degree in Wireless Communication from the Faculty of Electrical \& Elec-tronics Engineering, University Malaysia Pahang, Malaysia. Currently, he is an employer at Northern Technical University, Al-hawija Technical Institute. He has authored and co-authored numerous publications in international conferences and journals. His research interest includes LTE, energy-efficient cellular networks, adap-tive beamforming, smart antenna system. (drsuhel_hwj@ntu.edu.iq)

Haider Abdulameer Kamel holds a BSc.of electronic control Engineering from the Northern Technical University, Kirkuk Technical College in 2004 Holds a MSc. degree in electrical and electronic engineering from the Institute of Science at Istanbul University in 2016. Now I work as assistant lecturer at the Northern Technical University $\backslash \mathrm{Al}$ Hawija technical institution

Mokhaled N. A. Al-Hamadani, B.Sc Computer Science-College of Science-University of Kirkuk-Iraq. M.Sc Comuter Science-College of Arts and Sciences-The University of North Carolina at Greensboro-USA. Assistant lecturer-Northern Technical University- Iraq. Research interest. Big Data, Deep Learning, Machine Learning, Database, Networking, and any new techniques and subjects in computer science. 